\title{
Ensilaje de pasto Estrella Africana (Cynodon nlemfuensis) con la adición de melaza, suero de leche e inóculos microbiales
}

\author{
Cinthya Granados-Marín ${ }^{1}$, Rodolfo WingChing-Jones ${ }^{2}$ \& Augusto Rojas-Bourrillón ${ }^{2}$ \\ 1. Cooperativa de Productores de Leche, Dos Pinos R.L., Costa Rica; cmgm84@gmail.com \\ 2. Escuela de Zootecnia, Centro de Investigación en Nutrición Animal, Universidad de Costa Rica, Costa Rica; rodolfo.wingching@ucr.ac.cr, \\ augusto.rojas@ucr.ac.cr
}

Recibido 10-X-2013 • Corregido 7-II-2014 • Aceptado 9-II-2014

\begin{abstract}
African Star grass silage with molasses, whey and microbial additive. Nutritional and fermentation value of African star grass (Cynodon nlemfuensis) silage with application of molasses, mixtures of whey and molasses, and microbial inoculants were determined in the University of Costa Rica campus during 2009. Forage was harvested with 60 days of regrowth to $80 \mathrm{~cm}$ height and ensiled for 60 days in transparent plastic bags of one kilogram capacity. The treatments consisted in homemade inoculum (1 l/t MF), commercial inoculum (3,76g/t MF) and without application of inoculum, which were included molasses ( $3 \% \mathrm{p} / \mathrm{p})$, mixtures of molasses and whey ( $3 \% \mathrm{p} / \mathrm{p})$ in three relationships (2:1, 3:1 and 4:1) and a control without application of sources of sugars for a total of fifteen treatments with four replicates per treatment. The homemade inoculum decreased the DM content $(26,42 \pm 0,70 \%)$ and increased CP concentration $(11,68 \pm 0,20 \%)$, ash $(12,74 \pm 0,14 \%)$, NDF $(64,88 \pm 2,02 \%)$, $\operatorname{ADF}(36,51 \pm 1,53 \%)$, lignin $(4,29 \pm 0,39 \%), \mathrm{pH}$ value $(4,56 \pm 0.27)$, buffer capacity $\left(91.20 \pm 3.34 \mathrm{mEqNaOH} .100 \mathrm{~g}^{-1} \mathrm{DM}\right)$ and ammonia nitrogen $(1.78 \pm 0.28 \%)(\mathrm{N} / \mathrm{N}$ total). On the other hand, the commercial inoculant decreased the NDF content $(63,00 \pm 1,57 \%)$ and the lignin content $(2,87 \pm 0,17 \%)$ and buffer capacity $(76,87 \pm 8,77 \mathrm{mEqNaOH} / 100 \mathrm{~g} \mathrm{DM})$ of materials. Molasses and mixtures of molasses and whey application, increase DM, NDF, ADF, IVDMD, $\mathrm{pH}$ and ammonia nitrogen (N/N total). Homemade microbial inoculant reduced the energy density of the material. The results show that the better fermentative and nutritional value of silage was obtained with the application of mixture molasses and buttermilk in a 4:1 ratio with no inoculum added.
\end{abstract}

KEY WORDS: Crude protein, total digestible nutrients, neutral detergent fiber, carbohydrate source, homemade inoculum.

\section{RESUMEN}

Se determinó la composición nutricional y fermentativa del ensilaje de Estrella Africana (Cynodon nlemfuensis), con aplicación de melaza, mezclas de suero de leche y melaza, e inóculos microbiales, en las instalaciones de la Universidad de Costa Rica, San Pedro, durante el año 2009. El material se cosechó a una edad de 60 días con una altura de $80 \mathrm{~cm}$ y se ensiló por 60 días en bolsas plásticas transparentes de un kilogramo. Los tratamientos consistieron en inóculo elaborado en finca (1 l/t MF), inóculo comercial (3,76 g/t MF) y sin aplicación de inóculo, a los cuales se les incluyó melaza ( $3 \% \mathrm{p} / \mathrm{p})$, mezclas de melaza y suero de leche ( $3 \%$ $\mathrm{p} / \mathrm{p}$ ) en tres relaciones (2:1, 3:1 y 4:1) y un control sin aplicación de fuentes de azúcares para un total de quince tratamientos con cuatro repeticiones por tratamiento. El inóculo elaborado en finca disminuyó la MS $(26,42 \pm 0,70 \%)$ y aumentó la PC $(11,68 \pm 0,20 \%)$, cenizas $(12,74 \pm 0,14 \%)$, FDN $(64,88 \pm 2,02 \%), F D A(36,51 \pm 1,53 \%)$, lignina $(4,29 \pm 0,39 \%)$, el pH $(4,56 \pm 0,27)$, la capacidad buffer $(91,20 \pm 3,34 \mathrm{mEqNaOH} / 100 \mathrm{~g} \mathrm{MS})$ y el nitrógeno amoniacal $(1,78 \pm 0,28 \%)$ (N-N total). El inóculo comercial disminuye la FDN $(63,00 \pm 1,57 \%)$ y la lignina $(2,87 \pm 0,17 \%)$ y la capacidad buffer $(76,87 \pm 8,77 \mathrm{mEqNaOH} / 100 \mathrm{~g}$ MS) de los materiales. La aplicación de melaza y las mezclas de melaza y suero de leche, aumentan la MS, FDN, FDA, la DIVMS, el pH y el nitrógeno amoniacal (N-N total). El uso del inóculo elaborado en finca disminuye la densidad energética del material. Los resultados muestran que el material ensilado con aplicación de la mezcla de melaza y suero de leche en una relación 4:1 sin adición de inóculo presentó el mejor perfil fermentativo y nutricional.

PALABRAS CLAVE: Proteína cruda, nutrientes digestibles totales, fibra detergente neutro, fuentes de carbohidratos, inóculos elaborados en finca.
En zonas tropicales, la conservación de forrajes (por medio de las técnicas de ensilaje y henificación) y siembra de pastos mejorados son alternativas para disminuir el impacto negativo que las épocas de escasez de alimento pueden producir en los rumiantes. El ensilado o ensilaje es una técnica de conservación para materiales con niveles altos en humedad (Boschini \& Elizondo,
2003). Tal proceso se favorece con el uso de aditivos, que pueden mejorar el proceso fermentativo, el valor nutricional del material, según el aditivo utilizado y la cantidad adicionada.

En el trópico, la melaza de caña de azúcar es el aditivo de mayor uso en la elaboración de ensilajes, debido a su concentración de carbohidratos solubles que no 
se cristalizan para formar sacarosa (Perla, 1973) lo que aumenta la cantidad de azúcares en base seca en el material (Valencia, 2008). Además, se observa que aumenta la concentración de cenizas, calcio, proteína cruda y disminución de la fibra detergente neutro (Vargas, 1979), mejora la condición energética del alimento y favorece al desarrollo de los microorganismos deseados para una fermentación láctica (Méndez, 2000). La optimización del proceso fermentativo en los ensilajes depende de la cantidad existente de bacterias lácticas y el nivel de carbohidratos solubles del material (Tobía \& Vargas, 2000). Por lo que, la inclusión de inóculos microbiales permite incrementar la población de bacterias lácticas, lo que mejora la tasa de acidificación, por la producción de ácido láctico en lugar de ácido acético, ácido butírico, etanol y $\mathrm{CO}_{2}$ (Vendramini et al., 2010).

En Costa Rica, la experiencia del uso de esta técnica, está evaluada en maíz (Castillo, 2008; Cubero, 2008), plantas arbustivas (Boschini, 2003), leguminosas (Tobia, 2004; WingChing \& Rojas, 2006), pastos (Chaves, 1990) y rastrojos de cultivos agrícolas (López, 2008; Gutiérrez, Rojas, Dormond, Poore \& WingChing, 2003). En el caso del ensilaje de pasto Estrella Africana (Cynodon nlemfuensis Vanderyst) la información es escasa. Un único estudio publicado por Evangelista, Aparecida y Fernández (2000) sobre el ensilaje del pasto Estrella cosechado a los 45 días de rebrote y almacenado durante 35 días, demostró que este forraje podría preservarse bajo esta técnica, si se almacena de forma inmediata luego del corte o si es sometido a un proceso de deshidratación no mayor a tres horas.

De forma similar, las experiencias en Costa Rica, con el uso del suero de leche como aditivo en los ensilajes es escasa y se traduce a experiencias de campo, con evaluaciones subjetivas y sin ningún rigor científico. Un único trabajo descrito por Britos, Repetto, Garciarena \& Cajarville (2007), describen la evaluación del efecto de tres niveles de suero de leche en la conservación de forraje y mezclas de forrajes con leguminosas, donde indican, una adecuada fermentación y conservación del material. Tal experiencia, y lo que indica Valencia (2008), permite interpretar, que el suero de leche condensado puede igualar el valor nutricional de la melaza, lo que establece el precedente, para considerar la sustitución de la melaza por suero de leche y así disminuir los costos de elaboración del ensilado. Por tal motivo, el presente trabajo pretende generar información sobre las características nutricionales y fermentativas del ensilaje del pasto Estrella Africana, con aplicación de melaza, mezclas de suero de leche y melaza, e inóculos microbiales de tipo comercial y elaborados en finca.

\section{METODOLOGÍA}

Ubicación de la prueba. La cosecha del material a utilizar se realizó en la Finca "Ríos de Leche S.A" ubicada en el Distrito de San Jerónimo, Cantón de Moravia, San José, Costa Rica. Situada a una latitud norte de $10^{\circ} 06^{\prime} 35^{\prime}$ y a una longitud oeste de $84^{\circ} 21^{\prime} 58^{\prime}$ con una altitud de 1110 m.s.n.m. (Solano, 2009). El proceso de ensilado se llevó a cabo en las instalaciones de la Sede Rodrigo Facio y los análisis de laboratorio se efectuaron en el Centro de Investigación en Nutrición Animal, de la Universidad de Costa Rica.

Características del material vegetativo. La finca se dedica a la producción de ganado bovino de leche. El recurso forrajero se basa en pastoreo y corta del pasto a una edad entre los 45 y 60 días de rebrote. Poseen un sistema de fertilización orgánica con base en el compostaje de las excretas de los bovinos, las cuales se aplican al voleo en los potreros el propio día o un día después de haber terminado la ocupación en los potreros.

Preparación de los microsilos y toma de la muestra. Se recolectó material fresco (MF) del pasto Estrella Africana de 60 días de edad en el mes de mayo del 2009, con una altura aproximada del suelo al dosel de $80 \mathrm{~cm}$. La producción de biomasa de dicho forraje, calculada a partir del área de corta y el peso total del material, fue de 25 $000 \mathrm{~kg} / \mathrm{ha}$ MF. Posterior a su cosecha el material se picó a $2,5 \mathrm{~cm}$ de largo con ayuda de una picadora de cuatro cuchillas. Una vez distribuido el forraje en cada tratamiento, éste se depositó en bolsas plásticas transparentes para empaque al vacío con una capacidad de un kilogramo y un grosor de 0,0063mm. La extracción del aire se realizó mediante una bomba de succión y de forma inmediata se procedió a sellar las bolsas con cinta plástica adhesiva para evitar la pérdida del vacío. Al finalizar el tiempo del ensilado (60 días) se procedió a abrir los microsilos y se descartó las partes superficiales que pudieran estar en descomposición; luego se caracterizó de forma organoléptica los ensilajes (olor, color y textura) según la metodología descrita por Méndez (2000) y por último, se separó el material en dos muestras para el análisis fermentativo y nutricional.

Tratamientos. Se utilizó una asignación irrestricta al azar de los tratamientos utilizados, con cuatro repeticiones por cada uno, para un total de 60 microsilos. Dichos tratamientos consistieron en inóculos microbiales elaborado en finca, comercial y un control sin inóculo. Cada uno de los tratamientos mencionados se les aplicó 
fuentes de carbohidratos solubles al $3 \% \mathrm{p} / \mathrm{p}$, melaza al $3 \%$, tres mezclas de melaza: suero de leche en relaciones $2: 1(2 \%: 1 \%), 3: 1(2,25 \%: 0,75 \%)$ y $4: 1(2,4 \%: 0,6 \% \mathrm{p} / \mathrm{p})$ y un control sin fuente de carbohidratos. El suero se obtuvo un día antes de la cosecha del pasto, se conservó a $4^{\circ} \mathrm{C}$ en refrigeración y previo al experimento se expuso a temperatura ambiental. Se trabajo con un contenido de humedad en la melaza de $22,4 \%$, de $93 \%$ en el suero de leche y de $46,4 \%, 39,8 \%$ y $36,2 \%$ en las mezclas de melaza: suero de leche en las relaciones 2:1, 3:1 y 4:1 respectivamente.

Como inóculo comercial se empleó un cultivo de bacterias de ácido láctico que contiene 50 billones UFC por cada gramo de producto. En este caso se empleó la dosis que el fabricante recomienda, la cual es equivalente a $188 \mathrm{~g}$ del producto por cada 50 toneladas de material fresco (1 billón UFC/10 kg pasto).

En el caso del inóculo elaborado en finca a base de agua, melaza y cultivos microbiales, se produjo según la metodología descrita por Cubero, Rojas \& WingChing (2010), en donde se mezcla microorganismos eficientes $\left(\mathrm{EM}^{\oplus}\right)$, con melaza y agua. La concentración de microorganismos presentes en el inóculo utilizado fue de $1,0 \times 10^{4} \mathrm{UFC} / \mathrm{g}$ de bacterias, $<1,0 \times 10^{4} \mathrm{UFC} / \mathrm{g}$ de hongos, $5,0 \times 10^{3} \mathrm{UFC} / \mathrm{g}$ de levaduras y $2,4 \times 10^{7} \mathrm{UFC} / \mathrm{g}$ de Lactobacillus sp.

Variables evaluadas. A las muestras de ensilaje, se les analizó el contenido de materia seca (MS) en una estufa a $60{ }^{\circ} \mathrm{C}$ durante 48 horas, la proteína cruda (PC) se determinó mediante el método de Kjeldahl (AOAC, 2000), extracto etéreo (EE) y cenizas (Ce) se estimaron según la AOAC (2000), la fibra detergente neutro (FDN), fibra detergente ácido (FDA) y lignina a partir de Van Soest, Robertson y Lewis (1991), el nitrógeno ligado tanto a la FDN (N-FDN) como a la FDA (N-FDA) se determinó según Licitra, Hernandez y Van Soest. (1996) y la digestibilidad "in vitro" de la materia seca (DIVMS) (Van Soest \& Robertson, 1985).

Con respecto a las características fermentativas, la capacidad buffer y el pH del material se determinaron mediante la metodología descrita por McDonald (1981) y los valores de nitrógeno amoniacal ( $\mathrm{N}$-amoniacal/N-total) mediante los procedimientos descritos por Rojas (1985). Con base al valor de $\mathrm{pH}$ del ensilado de cada tratamiento y al tipo de inóculo aplicado (ausente, comercial y elaborado en finca), se seleccionó el material con el valor de $\mathrm{pH}$ más bajo, indicativo de una mejor fermentación. A este material, se le determinó el contenido de nutrimentos digestibles totales a una vez mantenimiento (NDT $1 \mathrm{X}$ ) y de energía, estimados a partir de las ecuaciones propuestas por Weiss (2004) y el NRC (2001).

Las características organolépticas que se evaluaron, fueron el color, el olor y la textura del material, según la metodología descrita por Méndez (2000). Con relación al color, este puede fluctuar desde un color verde (satisfactorio) hasta café oscuro (indeseable). Su olor puede variar de agradable o dulce (ácido láctico), avinagrado (ácido acético) o putrefacto (ácido butírico). Mientras que su textura puede diferir entre la conservación de la textura original del forraje hasta viscoso.

Descripción del análisis de varianza. La información nutricional y fermentativa de los silos fue analizada por medio de un modelo ANOVA (SAS, 2003), de acuerdo a la siguiente ecuación estadística:

$$
y_{i j}=\mu+M_{i}+I_{j}+(M x I)_{i j}+e_{i j k}
$$

$$
\text { donde: } \begin{aligned}
\mathrm{y}_{\mathrm{ij}} & =\text { observación individual } \\
\mu & =\text { media } \\
\mathrm{M}_{\mathrm{i}} & =\text { efecto de la melaza, } \mathrm{i}=(1,2,3,4,5) \\
\mathrm{I}_{\mathrm{j}} & =\text { efecto de los inóculos, } \mathrm{j}=(1,2,3) \\
(\mathrm{Mxl})_{\mathrm{ij}} & =\text { efecto de interacción } \\
\mathrm{e}_{\mathrm{ijk}} & =\text { error experimental, } \mathrm{k}=(1,2,3,4)
\end{aligned}
$$

Para la determinación de diferencias estadísticas entre las medias de los materiales ensilados se aplicó la prueba de Waller y Duncan mediante el programa de SAS (2003), donde se incluyeron todos los componentes bromatológicos y fermentativos de los materiales ensilados. Además en el análisis de los resultados, se describen las tendencias obtenidas de los efectos principales en dicha investigación.

\section{RESULTADOS}

\section{Características organolépticas de los ensilajes}

No se encontró presencia de hongos al abrir los microsilos posterior a los 60 días de fermentación. Todos los tratamientos presentaron un color verde-olivo, indicativo de una fermentación satisfactoria. En lo que concierne a la variable de olor, en los ensilajes se determinó un aroma dulce-avinagrado, lo cual supone la producción de ácido láctico y acético. Mientras que, en la textura del material, no se presentó ninguna muestra con viscosidad 
ni aglomeración, lo que indica un proceso de conservación deseable.

\section{Composición nutricional de los ensilajes}

Materia seca total (MST). En el cuadro 1, se observan comportamientos cuadráticos en el contenido de la MST, los cuales se atribuyen a la adición de carbohidratos (3\%p/p) y al tipo de inóculo aplicado: sin inóculo $\left(R^{2}=84,28\right)$, con inóculo comercial $\left(R^{2}=83,26\right)$ o elaborado en finca $\left(R^{2}=82,37\right)$. También, se determinó diferencias significativas debidas al inóculo aplicado $(p<0,001)$, la fuente de carbohidrato $(p<0,001)$ y la interacción inóculo-carbohidrato $(p<0,01)$. El inóculo microbial elaborado en finca redujo el contenido de MS significativamente, con respecto a la no aplicación del inóculo y al inóculo comercial. La adición de carbohidratos, presentó un efecto significativo en la conservación de la MS del material $(p<0,05)$. Según las fuentes que se evaluaron en este trabajo, se determinó que las mezclas de suero y melaza, no igualan el potencial de la melaza como aditivo en ensilajes, para disminuir el $\mathrm{pH}$ y conservar la proteína $(\mathrm{p}<0,05)$. Además se observa, un incremento en el contenido de MS al adicionar proporciones crecientes de melaza.

Proteína cruda (PC). El inóculo $(p=0,004)$ y el tipo de carbohidrato aplicado a los ensilajes $(p=0,009)$ afectan significativamente el valor de PC de las mezclas. Mientras que, en el caso de la interacción inóculo-fuente de carbohidrato $(p=0,18)$ no se obtuvo significancia alguna. El mayor contenido de PC se obtuvo en los tratamientos que se les aplicó el inóculo elaborado en finca $(p<0,05)$, a la vez, no se determinó diferencias en el contenido de PC por el uso del inóculo comercial y sin la aplicación en los materiales evaluados, lo cual se podría relacionar a residuos de proteína en el suero que se utilizó. De forma similar a la conservación de la MS, la aplicación de carbohidratos mejora el tenor de PC, pero no se nota diferencias entre las fuentes que se aplicaron ( $p>0,05$ ), lo que se podría relacionar en esta investigación a las mezclas de suero y melaza, las cuales podrían presentar un valor mayor de proteína cruda, que la melaza pura, por efecto de residuos de proteína en la elaboración del queso.

Cenizas. La cantidad de cenizas varía por el inóculo microbial aplicado $(p<0,0001)$ y la interacción inóculo y la fuente de carbohidrato, no así, por la fuente de carbohidrato $(p=0,13)$. Similar comportamiento al obtenido para el contenido de PC, se presentó en esta variable, donde, el inóculo microbial incrementó la cantidad de cenizas en los silos con respecto a los tratamientos sin inóculos e inóculo comercial, los cuales no varián entre sí $(p>0,05)$.

Fibra detergente neutra (FDN). La aplicación del inóculo microbial $(p<0,0001)$, la fuente de carbohidrato $(p<0,0001)$ y la interacción inóculo-carbohidrato $(p<0,006)$ afectan significativamente el contenido de FDN de los tratamientos evaluados. La no aplicación del inóculo microbial mostró los contenidos de FDN menores $(61,90 \pm 1,53 \%)$, en relación al valor de $63,00 \pm 1,57 \%$ con inóculo comercial y de $64,89 \pm 2,02 \%$ con el inóculo elaborado en finca $(p<0,05)$. Al comparar el contenido de FDN, según la inclusión de aditivos energéticos, se percibe, que la melaza estimula la disminución de FDN en los ensilajes $(p<0,05)$. El efecto de las mezclas de melaza y suero sobre la FDN, son menores que el tratamiento de solo melaza $(p<0,05)$, sin embargo, la FDN mostró una tendencia a disminuir respecto a la no aplicación de carbohidratos $(p<0,05)$.

Fibra detergente ácida (FDA). La FDA (Cuadro 1), se vio afectada de forma altamente significativa por el tipo de inóculo y la fuente de carbohidratos aplicada $(p<0,0001)$, mientras que la interacción entre el tipo de inóculo y los carbohidratos fue significativa $(p<0,009)$. Los valores mayores de FDA en los ensilados, se obtuvieron en los tratamientos con aplicación de inóculo elaborado en finca $(36,51 \pm 1,53 \%)(p<0,05)$ y no hubo diferencia significativa $(p>0,05)$ entre la no aplicación del inóculo $(35,58 \pm 1,07 \%)$ y el inóculo comercial $(35,24 \pm 1,26 \%)$. Con respecto a la aplicación de fuentes de carbohidratos, la melaza pura $(34,48 \pm 0,62 \%)$ estimula la reducción en el contenido de FDA. Las mezclas de melaza y suero de leche redujeron el contenido de FDA en el material ensilado con respecto al tratamiento sin aplicación de aditivos $(p<0,05)$, sin embargo su efecto es menor al encontrado con la aplicación de la melaza.

Lignina. Se encontró diferencias significativas en el contenido de lignina debidas a la aplicación del inóculo microbial $(p<0,0001)$, a la fuente de carbohidrato $(p<0,015)$ y a la interacción inóculo-carbohidrato $(p<0,0002)$. Según el inóculo aplicado, se diferencia el impacto del inóculo comercial $(2,87 \pm 0,17 \%)$ y el inóculo elaborado en finca $(4,29 \pm 0,39 \%)$.

Extracto etéreo (EE). No se encontró diferencias significativas $(p>0,05)$ entre los tratamientos analizados para el EE. Se obtuvo un promedio de $2,37 \pm 0,33 \%$ para las muestras sin aditivo microbial y de $2,17 \pm 0,06 \%$ para los 


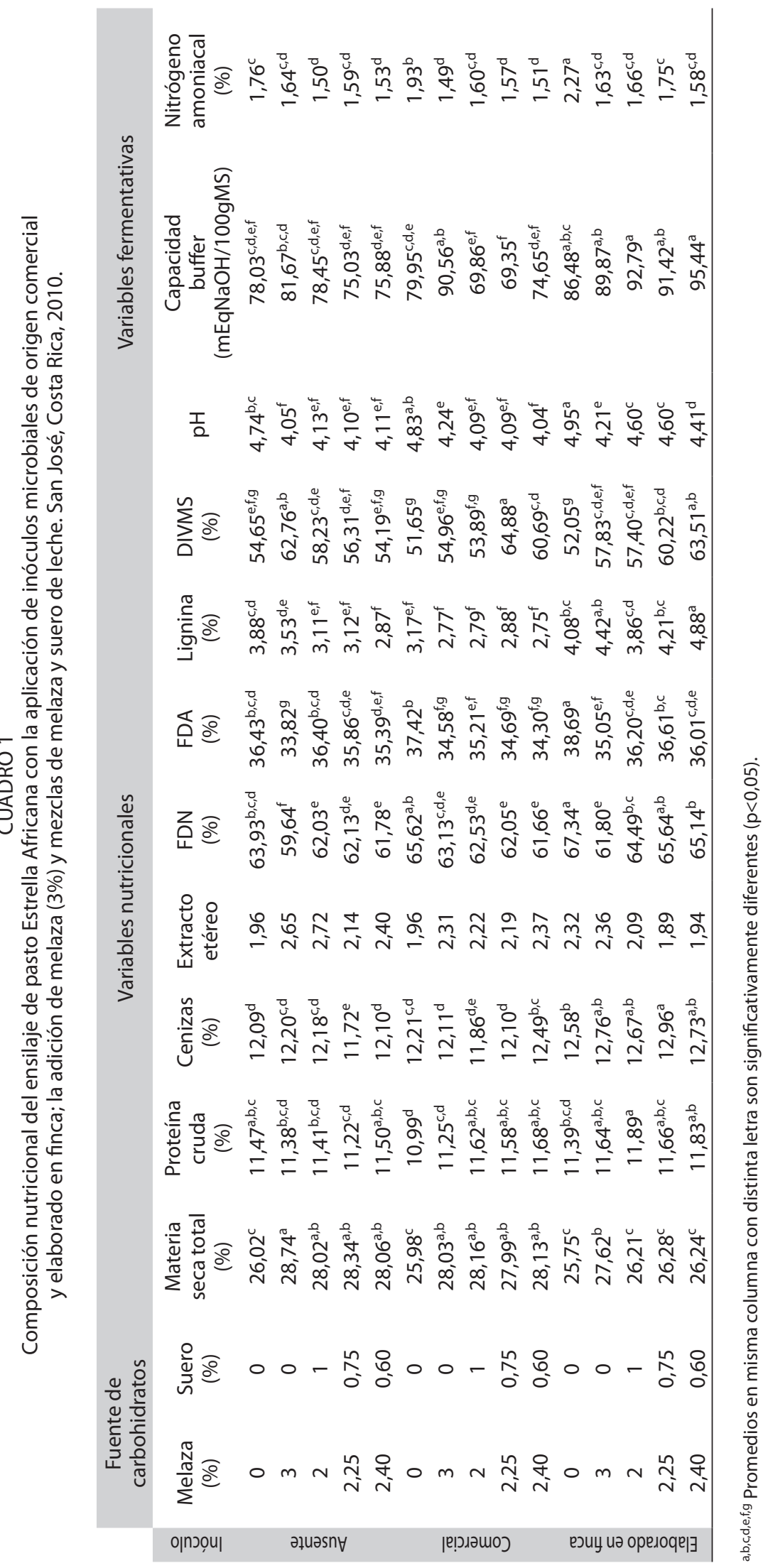


tratamientos a los que se les aplicó el inoculante. En los materiales con ausencia de inóculo, los valores fluctuaron entre 1,93 y $2,75 \%$ de EE, para las muestras con inóculo comercial se obtuvo un rango de 1,96 a 2,37\% y de 1,89 a 2,36\% para el inóculo elaborado en finca. Además, se notó un aumento en la concentración de EE al adicionar melaza ( $3 \% \mathrm{p} / \mathrm{p}$ ) con un nivel de $2,44 \pm 0,18 \%$ con respecto a los tratamientos sin fuentes de carbohidratos.

Digestibilidad"in vitro" de la materia seca (DIVMS). Los datos obtenidos para la DIVMS (51,65 a 64,88\%) son inferiores al rango indicado por Méndez (2000), para ensilajes de forrajes, los cuales fluctuán entre 65 a 70\% de digestibilidad (Cuadro 1). En este sentido, se determinó que el tipo de inóculo microbial no mejora la digestibilidad del material $(p=0,38)$, pero si se obtuvo diferencias significativas relacionada a la fuente de carbohidrato $(p<0,0001)$ y la interacción inóculo-carbohidrato $(p<0,0001)$. Con relación a las fuentes de carbohidratos, no se determinó diferencias entre el impacto de la melaza o las mezclas de melaza y suero de leche, pero el hecho de aplicar la fuente de carbohidrato al material, previo al compactado y sellado del ensilaje, genera en promedio un incremento de 7,69 unidades porcentuales en el aprovechamiento del material a nivel ruminal $(60,47 \pm 4,29 \%$ contra $52,78 \pm 1,63 \%)$.

\section{Variables fermentativas de los ensilajes}

pH. Se vio afectado de forma altamente significativa por el inóculo microbial, los carbohidratos aplicados y la interacción inóculo-carbohidrato $(p<0,0001)$. En el caso de los inóculos elaborados en finca, estos presentaron un valor promedio mayor $(4,56 \pm 0,27)$ con respecto a los demás tratamientos $(\mathrm{p}<0,05)$. Los valores de $\mathrm{pH}$, que indican problemas de fermentación del material, según lo descrito por Ojeda, Cáceres y Esperance (1991) (pH>4,0) se obtienen en los tratamientos que no se les aplicó carbohidratos $(4,84 \pm 0,11)(p<0,05)$.
Capacidad amortiguadora (mEqNaOH/100g MS). Los valores obtenidos para la capacidad buffer (CB) en los quince tratamientos evaluados se encuentran en un rango de 69,35 y 95,44 mEq NaOH/100 g MS. Estos valores se vieron afectados significativamente por el inóculo $(p<0,0001)$, la fuente de carbohidrato $(p<0,02)$ y la interación inóculo-carbohidratos $(p<0,05)$. En el caso de los inóculos elaborados en finca, se registró el valor mayor para la capacidad amortiguadora de 91,20 \pm 3,34 $\mathrm{mEq}$ $\mathrm{NaOH} / 100 \mathrm{~g} \mathrm{MS}(\mathrm{p}<0,05)$. La sintesis de ácidos no varió entre los tratamientos con aplicación de inóculos, producción expresada por el valor de capacidad amortiguadora del material. En el caso de la melaza, como fuente de carbohidrato, se registró la mayor cantidad de ácidos sintetizados (87,37 44,95 mEq NaOH/100 g MS), mientras que las mezclas de suero de leche y melaza, no mostró diferencias significativas entre los niveles de mezclas de suero de leche y melaza aplicadas, como también, con el tratamiento sin adición de carbohidratos.

Nitrógeno amoniacal (N/N total). La degradación de la proteína del material ensilado durante el proceso, es afectada por el inóculo ( $p<0,0001)$, la fuente de carbohidrato $(p<0,0001)$ y la interacción inóculo-carbohidrato $(p<0,001)$. En el caso de los inóculos elaborados en finca, este aumento del nitrógeno amoniacal es mayor que en los ensilajes con inóculo comercial y los tratamientos sin aplicación del inóculo $(p<0,05)$. No se encontró diferencias entre fuentes de carbohidratos aplicadas $(p<0,05)$.

Estimación del contenido energético del ensilaje Se estimó el contenido de nutrientes digestibles totales $\left(\right.$ NDT $_{1 \mathrm{x}}$ ) y la concentración energética, la cuál se separó en energía digestible (ED), energía metabolizable (EM), energía neta para mantenimiento (ENm), energía neta para ganancia de peso (ENg) y energía neta de lactancia (ENI), expresados en megacalorías por kilogramo de materia seca (Cuadro 2). Análisis realizados al ensilado que

\section{CUADRO 2}

Contenido energético (1X) estimado del ensilaje de estrella africana, con y sin la aplicación de inóculo microbiales de origen comercial y elaborados en finca. San José, Costa Rica, 2010.

\begin{tabular}{lcccccc}
\multicolumn{1}{c}{ Inóculo } & $\begin{array}{c}\text { NDT } \\
(\%)\end{array}$ & $\begin{array}{c}\text { ED } \\
\left(\text { Mcal.kg }^{-1}\right)\end{array}$ & $\begin{array}{c}\text { EM } \\
\left(\text { Mcal.kg }^{-1}\right)\end{array}$ & $\begin{array}{c}\left.\text { ENm (Mcal.kg })^{-1}\right) \\
\text { ENg (Mcal.kg }\end{array}$ & $\begin{array}{c}\text { ENI } \\
\left(M^{-1}\right)\end{array}$ \\
Ausente & $56,23^{\mathrm{a}} \pm 1,19$ & $2,48^{\mathrm{a}} \pm 0,06$ & $2,03^{\mathrm{a}} \pm 0,04$ & $1,19^{\mathrm{a}} \pm 0,04$ & $0,62^{\mathrm{a}} \pm 0,04$ & $1,26^{\mathrm{a}} \pm 0,03$ \\
Comercial & $56,49^{\mathrm{a}} \pm 0,54$ & $2,49^{\mathrm{a}} \pm 0,03$ & $2,05^{\mathrm{a}} \pm 0,02$ & $1,20^{\mathrm{a}} \pm 0,02$ & $0,63^{\mathrm{a}} \pm 0,02$ & $1,26^{\mathrm{a}} \pm 0,01$ \\
Elaborado en finca & $53,03^{\mathrm{b}} \pm 0,94$ & $2,34^{\mathrm{b}} \pm 0,04$ & $1,92^{\mathrm{b}} \pm 0,03$ & $1,07^{\mathrm{b}} \pm 0,03$ & $0,52^{\mathrm{b}} \pm 0,03$ & $1,18^{\mathrm{b}} \pm 0,02$ \\
\hline
\end{tabular}

${ }^{a, b}$ Promedios en misma columna con distinta letra son significativamente diferentes $(p<0,05)$. 
presentó el valor menor de $\mathrm{pH}$, según la aplicación del inóculo (sin inóculo, con inóculo comercial y con inóculo elaborado en finca). Según los valores obtenidos en los ensilajes con aplicación de inóculo elaborado en finca, se determina una reducción en el contenido energético de los materiales $(p<0,05)$.

\section{DISCUSIÓN}

Con respecto al contenido de MST, el uso de los inóculos microbiales mejoran la fermentación y su conservación, pero depende de la población existente en el inóculo aplicado (Vendramini et al., 2010). En el caso de esta investigación, los microorganismos que predominan en los inóculos elaborados en finca presentan características de descomponedores de materia seca (Microorganismos eficientes EM ${ }^{\circledR}$ ). En el caso de la aplicación de melaza, al poseer menor cantidad de humedad que el resto de los aditivos usados (inóculos y suero de leche), ayuda en el incremento de MST del material ensilado. Esta misma tendencia la encontraron Vallejo, Benavides \& Esquivel (1994), donde determinaron un aumento en el contenido de MS de 26,9 a $30,4 \%$ por la adición del 5\% de melaza en los ensilajes de morera. En el caso de los niveles de proteína, los ensilajes con aplicación de inóculo $(11,55 \pm 0,18 \%)$, presentaron valores mayores al promedio que señalan Vendramini et al. (2010) para los ensilajes de pasto Estrella tratados con inoculantes (10,9\%). Dicha tendencia podría explicarse, por la diversidad y cantidad de microorganismos existentes en la mezcla, la edad de cosecha, manejo agronómico del cultivo y aditivos utilizados. Tal similitud en el contenido de proteína cruda al aplicar melaza o las mezclas de melaza y suero, se podría relacionar al bajo contenido de PC de la melaza $(\sim 3,66 \% \mathrm{MS})$ y el suero de leche $(\sim 0,80 \%$ MS). Según experiencias obtenidas por Jones, Heinrichs, Roth y Ishler (2004) y Chaves (2005) en ensilajes de maíz y sorgo, el tratamiento sin aplicación de aditivos del ensilaje de pasto Estrella Africana $(11,47 \%)$ presentó un contenido superior de PC que el ensilado de maíz y sorgo $(9,1 \%)$, y sorgo forrajero $(6,83 \%)$ respectivamente. En cambio, presenta un valor similar $(11,47 \%)$ al obtenido para el ensilaje de Cratylia (11,77\%) (Chaves, 2005), lo que potencia su uso en la alimentación de rumiantes. Al valorar el contenido de cenizas del ensilado de Estrella Africana (12,09\%) obtenido en este estudio, se presentan contenidos mayores a los informados por López (2008) para el ensilaje de rastrojo de piña (10,8\%), para el ensilado de Arachis pintoi (CIAT 18744) a 8 semanas de rebrote $(10,26 \%)$ (WingChing \& Rojas, 2006), a los ensilados de mezclas de maíz y vigna (Castillo, 2008) y al ensilado de maíz (Cubero et al., 2010). Comportamiento, que podría indicar un mayor control del aporte de minerales (cantidad y porporción) por este ensilado, cuando forma parte de la ración total de animales rumiantes.

El comportamiento de la pared celular del pasto estreIla a nivel de FDN, FDA y la lignina, presenta similitud en respuesta a la aplicación de inoculos con respecto al trabajo de Cubero (2008) en ensilajes de maiz. Al comparar el contenido de FDN de los tratamientos con adición de inóculos, con los descritos por Vendramini et al. (2010) en ensilados con inóculos de Estrella Africana $(65,4 \%)$, pasto Elefante $(66,6 \%)$ y Cynodon $s p$. $(68,5 \%)$, se determinan valores inferiores en esta investigación, lo cual se podría relacionar, con la edad y condiciones de cosecha del material, el tipo de microorganismo en el inóculo y las características propias de las investigaciones, como tipo de silo utilizado. La aplicación de carbohidratos al ensilaje, permite un mejor proceso fermentativo asociado al aumento de azúcares naturales en el material. Chaves (2005) y Bernal, Chaverra, Arciniegas y Acevedo (2005) obtuvieron resultados similares al aplicar melaza en materiales a ensilar en el contenido de FDN. Esta reducción de la pared celular, supone un beneficio en el consumo del material y una reducción en su efecto de llenado físico en los animales al tener menor tiempo de retención dentro del rumen (Holland, Kezar \& Quade, 1995). En un estudio realizado por Britos et al. (2007) se concluyó que el uso de suero de leche al $2 \% \mathrm{p} / \mathrm{p}^{-1}$ induce un aumento en los niveles de FDN en los ensilajes de forrajes $(60,05 \%)$ comparado al uso de melaza pura como aditivo $(54,91 \%)$, situación que se percibe en este caso aún al utilizar un nivel inferior del $1 \%$. Contrario al mismo estudio, en la presente investigación se manifiesta un aumento en la concentración de FDN al incrementar las cantidades de suero de leche como aditivo en el inóculo elaborado en finca. Una posible explicación a dicho comportamiento, se sustenta en que el suero de leche sea un sustrato de lenta fermentación, lo que provoca que se disminuya la degradabilidad de la fracción fibrosa y se hace uso del contenido de carbohidratos solubles propio del cultivo. Al respecto, Weisbjerg, Hvelplund \& Bibby (1998) demostraron que la lactosa tiene una tasa de fermentación ruminal correspondiente a la mitad de la tasa de la sucrosa (540 contra 1302\%/h). La tendencia obtenida para el contenido de FDA de incrementarse, podría relacionarse a la población microbial presente en el inóculo artesanal, pues dichos microoganismos crean un efecto de estabilidad del forraje fermentado al disminuir la descomposición de los componentes fibrosos y utilizar los componentes más disponibles o no fibrosos, lo que provoca un aumento en la concentración de la FDA en el material que se ensiló (Cubero, 2008). Otro aspecto 
a considerar en la reducción de la FDA además de una mayor actividad de los microroganismos, podria ser una posible participación de la hemicelulosa en el proceso fermentativo (Cubero, 2008). Dicha disminución, mejora la digestibilidad del material a nivel ruminal (Holland et al., 1995). El dato de FDA obtenido en los ensilajes de Estrella Africana (36,43\%) es inferior a los encontrados por Vendramini et al. (2010) para el pasto Estrella $(41,3 \%)$, especies de pasto Bermuda $(42,23 \%)$ y el pasto Tifton 85 (41,1\%). En cambio, presenta un valor similar a los ensilados de rastrojo de piña con 35\% de FDA (López, 2008). Situación que podría potenciar su uso como fuente forrajera en sistemas de producción de rumiantes en condiciones tropicales. Estos resultados coinciden con lo obtenido en ensilajes de máiz (2,32\%) por Cubero (2008), donde obtiene valores mayores de lignina en los tratamientos que se les adicionó inóculo elaborado en finca $(5,18 \%)$. Dicho autor, lo relaciona con el aumento obtenido en el contenido de FDA, ya que dicha fracción está constituida por la pared celular primaria donde se incluye la lignina. En cambio, Ferreira et al. (2006), no encontraron diferencias en el contenido de dicha variable a partir del uso de aditivos bacteriales en ensilajes de pasto Estrella. La concentración de lignina en los ensilados de pasto Estrella Africana (3,88\%) son inferiores a los obtenidos por Jones et al. (2004) para ensilados de sorgo $(6,5 \%)$ y soya $(6,5 \%)$. Tal comportamiento se debe a que el material inicial contenía niveles bajos de lignina, por lo que es de esperar que luego de su fermentación se mantenga en un rango similar e inferior a otros forrajes como gramíneas o leguminosas.

El aporte de EE por parte del ensilado de Estrella Africana $(1,96 \%)$ es menor con respecto al promedio nacional de los pastos tropicales, cuyo valor es de $2,18 \%$, el cual varía entre 1,98\% para el pasto Estrella a 2,65\% para el pasto San Juan (Sánchez \& Soto, 1996). Lo cual indica, que no es una fuente de energía a considerar en el programa de alimentación, faltante que se debe de solventar con otros materiales. En el caso de la digestibilidad del material, su aumento se podría relacionar al aporte de carbohidratos solubles, los cuales permiten y propician una mayor actividad de los microrganismos, lo que mejora la conservación de la fracciones de mayor degradabilidad del forraje ensilado.

El aumento del pH en los materiales con aplicación de inóculos, podría relacionarse a las especies de microorganismos existentes, los cuales producen otros compuestos que elevan el $\mathrm{pH}$ o aumentan la capacidad amortiguadora del material. Según el análisis realizado a dicho inóculo, se determinó la presencia de levaduras, hongos y bacterias. Según Carrillo (2003), la producción de ácido láctico, crea un ambiente ácido que favorece el crecimiento de levaduras, las cuales tienden a producir alcoholes, ésteres o carbohidratos al descomponer el azúcar, lo que podría provocar un aumento del $\mathrm{pH}$, por las características de estos productos de la fermentación (Carrillo, 2003). En cambio, se favorece la reducción del $\mathrm{pH}$ en el material, por adición de la melaza, debido a que éstos son fermentados por los microorganismos para la producción de ácidos y así se crea un ambiente favorable para la conservación del mismo (Tobía \& Vargas, 2000). Al comparar el efecto promedio de las mezclas de melaza y suero de leche, con el de la melaza pura, se obtiene una tendencia en el aumento de la acidez menor en el material ensilado $(p<0,05)$. Los datos obtenidos de $\mathrm{pH}$, se encuentran dentro del rango de 4,3 a 4,8 descrito por Chaves (2005) para ensilajes de pastos tropicales, por lo que, según la clasificación mencionada por Mendez (2000), estos materiales se catalogan de calidad media. Además, Vendramini et al. (2010) mencionan que los ensilajes de forrajes tropicales se caracterizan por tener elevados contenidos de ácido acético, lo que produce una declinación leve en el $\mathrm{pH}$, ya que éste es un ácido graso volátil más débil que el ácido láctico.

La capacidad amortiguadora del ensilaje de estrella africana aumentó con la aplicación de inóculos, lo cual podría asociarse al contenido de microorganismos presentes, que producen el deterioro de la materia orgánica, lo que afecta la producción de ácido láctico y acético, y el valor de pH de los materiales ensilados (López, 2008). Las mezclas de suero de leche parecen no estimular la fermentación dentro de los materiales (Gutiérrez et al., 2003), ya que la capacidad amortiguadora de los mismos no varió significativamente. En cambio, el aporte de carbohidratos al proceso fermentativo reduce la degradación de las proteínas en el forraje. Según los valores obtenidos de nitrógeno amoniacal, los ensilajes de Estrella africana con aplicación de melaza y mezclas de melaza y suero de leche, se consideran ensilajes de excelente calidad, debido a que los valores obtenidos están por debajo del $5 \%$ de nitrógeno amoniacal con respecto al $\mathrm{N}$ total (Peña \& Del Pozo, 1992).

El valor energetico del ensilaje fue similar al descrito por Cubero (2008) en ensilaje de maíz, donde la adición de inóculo elaborado en finca, aún sea utilizado en dosis altas, no mejora los contenidos energéticos del ensilaje de maíz. Lo que se relacionó a un nivel mayor en los componentes de la pared celular, ya que el contenido de la fibra tiene una correlación negativa con el contenido energético en el forraje (Sánchez \& Soto, 1998), por su relación con la digestibilidad del material (Cubero, 2008). En el caso de los contenido de NDT para los ensilados sin inóculo $(56,23 \pm 1,19 \%)$, en promedio son superiores a los obtenidos por Sánchez y Soto (1999) para forrajes 
frescos, como el pasto Estrella (53,8\%) y el Brachiaria ruzi $(53,7 \%)$, similar para el pasto Kikuyo $(56,7 \%)$, pero inferior a los ensilajes de rastrojo de piña con un valor de 59,0\% (López, 2008). De igual manera, los contenidos de energia digestible de los materiales sin inóculo de la presente investigación se asemejan a los valores de forrajes tropicales en fresco, por ejemplo, el pasto Estrella presenta un valor promedio de $2,37 \mathrm{Mcal} / \mathrm{kg} \mathrm{MS}$, el pasto San Juan un valor de 2,40Mcal/kg MS y el Kikuyo con 2,50 de Mcal/kg MS (Sánchez \& Soto, 1999). En general, los ensilados de pasto Estrella africana son una opción para la alimentación de animales rumiantes, pero requieren de ser suplementados con una fuente de carbohidratos y proteína que complemente las necesidades nutricionales de los animales y así evitar deficiencias nutricionales que se cuantifican en la reducción de la productividad y reproductividad de los animales alimentados con estos materiales.

\section{AGRADECIMIENTOS}

Al Centro de Investigación de Nutrición Animal (CINA) y al Centro de Investigaciones Agronómicas (CIA) de la Universidad de Costa Rica y a la Finca "Ríos de Leche S.A."

\section{REFERENCIAS}

AOAC (Association of Official Agricultural Chemists). (2000). Official methods. $17^{\text {th }}$ Ed. Washington D.C., USA: AOAC.

Bernal, J., Chaverra, H., Arciniegas, A., \& Acevedo, G. (2005). Ensilaje, heno y henilaje: tipos, métodos y nuevas tecnologías. $2^{\text {da }}$ Ed. Bogotá, Colombia: Angel Agro-Ideagro.

Boschini, C. (2003). Características físicas y valor nutritivo del ensilaje de Morera (Morus alba) mezclado con forraje de maíz. Agronomía Mesoamericana, 14(1), 51-57.

Boschini, C., \& Elizondo, J. (2003). Curso teórico y práctico de ensilaje de forrajes. San José, Costa Rica: Editorial de Universidad de Costa Rica.

Britos, A., Repetto, J., Garciarena, D., \& Cajarville, C. (2007). Efecto del suero de queso como aditivo de ensilajes de pastura sobre la conservación, los azúcares solubles y la producción de gas in vitro. Agrociencia, XI(2), 72-77.

Carrillo, L. (2003). Los hongos de los alimentos y forrajes. Buenos Aires, Argentina: Universidad Nacional de Salta.

Castillo, M. (2008). Valor nutricional y capacidad fermentativa del ensilaje de maíz (Zea mays) cultivado en asocio con vigna (Vigna radiata) a dos densidades de siembra. (Tesis de licenciatura). Universidad de Costa Rica, San José, Costa Rica.
Chaves, A. (1990). Evaluación de los parámetros fermentativos y nutricionales de la mezcla de pasto King grass (Pennisetum purpureum), la pulpa y fruto integral de pejibaye (Bactris gaspass. HBK), ensilados en microsilos. (Tesis de licenciatura). Universidad de Costa Rica, San José, Costa Rica.

Chaves, C. (2005). Calidad y consumo de mezclas de Cratylia argentea y sorgo forrajero (Sorghum bicolor (L.) Moench) con y sin melaza, ensiladas en bolsas plásticas. (Tesis de licenciatura). Universidad de Costa Rica, San José, Costa Rica.

Cubero, J. (2008). Comparación del efecto de inóculos comerciales y artesanales sobre el proceso fermentativo del ensilaje de maíz (Zea maiz). (Tesis de licenciatura). Universidad de Costa Rica, San José, Costa Rica.

Cubero, J., Rojas, A. \& WingChing, R. (2010). Uso de inóculos microbiales elaborado en finca en ensilajes de maíz. Valor nutricional y fermentativo. Agronomía Costarricense, $34(2), 237-250$.

Evangelista, A., Aparecida, J., \& Fernández, T. (2000). Avaliação de algumas características da silagem de gramínea Estrela roxa (Cynodon nlemfuensis Vanderyst). Revista Brasileira de Zootecnia, 29(4), 941-946.

Ferreira, F., Nussio, L., Maluf,C., Prudencio, F., Michelini, R., Mari, L., \& De Almeida, P. (2006). Características de fermentação e composição químico-bromatológica de silagens de capim-tifton 85 confeccionadas com cinco teores de matéria seca. Revista Brasileira de Zootecnia, 35(1), 7-20.

Gutiérrez, F., Rojas, A., Dormond, H., Poore, M., \& WingChing R. (2003). Características nutricionales y fermentativas de mezclas ensiladas de desechos de piña y avícolas. Agronomía Costarricense, 27(1), 79-89.

Holland, C., Kezar, W., \& Quade, Z. (1995). The Pioneer Forage Manual. A Nutricional Guide. Des Moines, lowa, USA: Pioner Hi-Bred International, Inc.

Jones, C., Heinrichs, A., Roth, G., \& Ishler, V. (2004). From harvest to feed: Understanding silage management. Penn State College Agricultural Sciences, Pennsylvania, USA: Pennsylvania State University.

Licitra, G., Hernandez, T., \& Van Soest, P. (1996). Standardization of procedures for nitrogen fractionation of ruminant feeds. Animal Feed Science and Technology, 57(4),347-358.

López, M. (2008). Valoración nutricional de los rastrojos de piña (Ananas comosus) como una alternativa forrajera de bajo costo para la alimentación del ganado. (Tesis de licenciatura). Universidad de Costa Rica, San José, Costa Rica.

McDonald, P. (1981). The biochemistry of silage. University of Edinburgh, Chichester: John Wiley \& Sons.

Méndez, M. (2000). Aprendamos sobre ensilajes. San José, Costa Rica: Instituto Nacional de Aprendizaje.

NRC (National Research Council). (2001). Nutrient Requirements of Dairy Cattle. $7^{\text {th }}$ rev. ed. Washington, D.C., USA: National Academy Press. 
Ojeda F., Cáceres, O., \& Esperance, M. (1991). Conservación de forrajes. La Habana, Cuba: Editorial Pueblo y Educación. $80 \mathrm{p}$.

Peña, P., \& Del Pozo, P. (1992). Explotación de pastos y forrajes. La Habana, Cuba: ISCAH.

Perla, F. (1973). Crecimiento de novillas en pastoreo con diferentes disponibilidades de pasto y un concentrado líquido de melaza. (Tesis de maestría). Centro Agronómico Tropical de Investigación y Enseñanza (CATIE), Cartago, Costa Rica.

Rojas, A. (1985). Effect of rolled corn silage on digestion of nutrients and feedlots performance of growing steers. (Tesis de maestría). lowa State University, Ames, lowa, USA.

Sánchez, J., \& Soto, H. (1996). Estimación de la calidad nutricional de los forrajes del cantón de San Carlos. I. Materia seca y componentes celulares. Nutrición Animal Tropical, 3(1), 3-18.

Sánchez, J., \& Soto, H. (1998). Estimación de la calidad nutricional de los forrajes del cantón de San Carlos. II. Componentes de la pared celular. Nutrición Animal Tropical, 4(1), 3-23.

Sánchez, J., \& Soto, H.. (1999). Estimación de la calidad nutricional de los forrajes del cantón de San Carlos. III. Energía para la producción de leche. Nutrición Animal Tropical, 5(1), 31-49.

SAS. (2003). SAS 9.1.3 for Windows. Service Pack 4.Win_Pro plataforma. Copyright (c) 2002-2003 by SAS Institute Inc. Cary, N.C. USA.

Solano A. (2009). Situación de la finca Ríos de Leche S.A. Mimeografiado. San Jerónimo de Moravia, San José, Costa Rica.

Tobía, C. (2004). Introducción del ensilaje de soya en un sistema de producción intensiva de leche en el trópico húmedo de Costa Rica. (Tesis de doctorado). Universidad de Costa Rica, San José, Costa Rica.

Tobía, C., \& Vargas, E. (2000). Inóculos bacterianos: una alternativa para mejorar el proceso fermentativo en los ensilajes tropicales. Nutrición Animal Tropical, 6(1), 129-143.
Valencia, J. (2008). El suero de quesería y sus posibles aplicaciones Parte 1/3. Mundo lácteo y cárnico, Marzo/Abril, 4-6.

Vallejo, M., Benavides, J., \& Esquivel, J. (1994). Observaciones sobre el consumo de ensilajes de follaje de árboles y arbustos por cabras. En Benavides, J. (ed.). Árboles y arbustos forrajeros en América Central. Cartago, Costa Rica: CATIE 1 (Serie técnica, Informe técnico No. 236).

Van Soest, P., \& Robertson, J. (1985). Analysis of forages and fibrous feeds. Ithaca, New York: Cornell University.

Van Soest, P., Robertson, J., \& Lewis, A. (1991). Methods for dietary fiber, neutral detergent fiber, and non starch polysaccharides in relation to animal nutrition Symposium: Carbohydrate methodology, metabolism, and nutritional implications in dairy cattle. Journal of Dairy Science, 74, 3583-3597.

Vargas, R. (1979). Determinación de la composición química y el valor nutritivo del pasto Elefante (Pennisetum purpureum) ensilado en microsilos con tres niveles de melaza. (Tesis de licenciatura). Universidad de Costa Rica, San José, Costa Rica.

Vendramini, J., Desogan, A., Silveira, M., Sollenberger, L., Queiroz, O., \& Anderson, W. (2010). Nutritive value and fermentation parameters of warm-season grass silage. The Professional Animal Scientist, 26 (2010), 193 -200.

Weisbjerg, M., Hvelplund, T., \& Bibby, B. (1998). Hydrolysis and fermentation rate of glucose, sucrose and lactose in the rumen. Acta Agriculturae Scandinavica, Section A Animal Science, http://www.informaworld.com/smpp/ti tle $\mathrm{db}=$ all $\sim$ content $=$ t713690045 tab=issueslist $\sim$ branc hes $=48-\mathrm{v} 4848(1), 12-18$.

Weiss, W. (2004). Fine-tuning energy calculations. Proceedings Tri-State Dairy Nutrition Conference. Purdue University, Michigan State University, Ohio State University, United States.

WingChing, R., \& Rojas, A. (2006). Composición nutricional y características fermentativas del ensilaje de maní forrajero. Agronomía Costarricense, 30(1), 87-100. 